\title{
The Effects of Family Health and Psychological Strength Perceived by Job-seekers on Job Search Efficacy
}

\author{
Kyeng-my Song1), Sung-je Cho2)
}

\begin{abstract}
The purpose of this study was to identify the effect of job health perceived family health and psychological strength on Job search efficacy. The subjects of this study were 128 female job-seekers in their 40 s to 50 s those who are selected only answered sincerely out of 200 female job-seekers in Ulsan Metropolitan City. For the analysis method, frequency analysis, reliability analysis, correlation analysis were performed using SPSS program, and regression analysis were performed on causality among variables. First, as a result of analyzing the relationship between job seekers' perceived family health and job search efficacy, the sub-factors of family health such as mutual respect and acceptance, economic stability and cooperation, and family culture and social participation were found to have a positive effect on job search efficacy. On the other hand, family elasticity and qualitative bonding factors were verified to have no significant effect on Job search efficacy. Second, an analysis of the relationship between the psychological strength of the job-seeker and the effect of the Job search efficacy showed that the control factor among the sub-components of the psychological strength had a positive and significant effect on the job-seeker's Job search efficacy. On the other hand, factors of involvement and challenge have shown no significant impact on Job search efficacy. This study is thought to be the basis for preparing programs for job-seekers to enhance their competence.
\end{abstract}

Keywords: Job-seekers, Perceived Family Health, Psychological Strength, Job Search Efficacy, Mutual Respect and Acceptance

\section{Introduction}

\subsection{The Necessity of Study}

The reality is that the number of jobs that will disappear as the country shifts from an industrialized society to the fourth industrial revolution era is increasing. Han-joon Kim (2017)[1] studies report that job losses will be 43.3 percent due to the fourth industrial

Received(March 03, 2020), Review Result(1st: April 01, 2020, 2nd: May 25, 2020), Accepted(June 25, 2020)

1) (Ph. D. course/doctorate course) 02838 Dept. Department of Regional and Welfare Administration Department, Dongbang Culture Graduate Univ., 28 Sungbok-Ro, Sungbokdong, Seoul, Korea email: glorysong66@naver.com

2) (Professor, Corresponding Author) 02838 Dept. Department of Regional and Welfare Administration Department, Dongbang Culture Graduate Univ., 28 Sungbok-Ro, Sungbokdong, Seoul, Korea email: chosj715@daum.net 
revolution, while job growth will be 13.4 percent. As a result, the problem of job search in the modern society is serious, such as youth unemployment and job inequality. According to the National Statistical Office (2019) data, the number of young people preparing to get a job recently exceeds 700,000 in Korea, the highest number in 13 years. These results show that the job market is not very bright. Therefore, it became necessary to study active job search measures for job-seekers to address their burdens and prolonged job preparation, psychological anxiety, mental pain, and social problems. In particular, it is reported that job-seekers' Job search efficacy is a very important variable in their job search activities(Hye-jung Gwak, 2011)[2].

Job search efficacy refers to a belief in an individual's ability to successfully carry out various job activities (Jung-hyun Cho et al., 2018)[3]. Those who engage in these activities are called job-seekers. Looking at previous studies on Job search efficacy, family members' support is very important for job seekers' job search efficacy. This is because it is reported that Job search efficacy and social support affect career-short women's job search activities (Kang-hee Goo, 2018)[4]. It also has been reported that Job search efficacy affects job preparation activities (Hana Bum, 2018)[5]. Therefore, in order to prevent job-seekers from giving up their job search activities and induce them to continue their job search activities, various factors that determine Job search efficacy should be studied.

The following are studies of family support for job seekers and their Job search efficacy. The study of Pil-ju Ham (2015)[6] indicates that the higher the family support for female immigrants is, the higher job search efficacy is. From the perspective of family support within the scope of social support, it is found that social support affects job seekers' job search goals and motivation.

Hyun-mi Lee (2014)[7] reported a significant correlation between the two variables after analy zing the impact of social support on overall Job search efficacy for female job-seekers who are seeking re-employment. In summing up the above discussions, it can be seen how positive the support of family members has in determining job openings. Family health is defined as to be able to live a satisfying life as a member of society by smoothly performing the functions of in dividuals and family members based on the stability of family' (Seonghee Park, 2018)[8]. There are five components of family health. 'First family resilience means coordination, expression of appreciation and love, expression of respect for opinions, and smooth response among family members. Second, mutual respect and acceptance mean trust among family members, sense of belonging and respect, bond and accepting family relations. Third, quality bonds mean activitie $\mathrm{s}$, issues and intimacy shared by families. Fourth, economic stability and cooperation means eff 
orts for economic stability, and the fifth is family culture and social participation, which means interest and participation in the family's tradition, culture, and community" (Park Sung-hee, 201 8)[8]. However, there has been no study on factors affecting Job search efficacy in terms of a $f$ amily health factor for job seekers. Therefore, research on family health is needed in orde $r$ to prevent job seekers from giving up on job search activities and continuously lead them to job serach activities.

Meanwhile, studies on psychological factors affecting Job search efficacy of job-seekers are as follows. Ji-yeon Kim and Gi-hak Lee (2015)[9] studied the effect of self-elasticity, which is a sub-variable of positive psychological capital, on career-determined self-effectiveness and job preparation activities. As a result, career decision-making self-effectiveness completely mediated university students' self-elasticity and career preparation activities. Shin-young Park (2017)[10] said that positive psychological capital has positive influence on career preparation activities by verifying the medial effect of social support in the relationship between positive psychological capital and career preparation action of university students. In summing up the above discussions, it can be seen that positive psychological capital has a positive effect on career preparation activities. Psychological strength refers to 'personality traits believing and actively engaging in one's influence on the environment even in the face of a difficult situation, minimizing the reaction to stress and accepting and challenging it as a process of growth' (Kyung-Ah Kim, 2019)[11]. The sub-factors of psychological strength can be explained as involvement, control, and challenge as follows. 'Involvement means putting a value on a goal and immersing one's own energy even if it is difficult. Control refers to the belief that you can control or influence yourself more or less about the external situation through a coping method. Challenge is a willingness and attitude to overcome as a chance of growth rather than giving up easily when faced with stress" (Kyung-A Kim,2019)[11]. There has been no study on factors affecting Job search efficacy in terms of a psychological strength factor for job-seekers. Therefore, research on psychological strength is needed to prevent job-seekers from giving up their job search activities and to continue to lead them to job search activities.

This prior study results in the need to study the effects on their job effectiveness of job-seekers. In the existing studies, some case studies related to job preparation have been conducted for job-seekers, but there are insufficient studies on perceived family health, psychological strength and Job search efficacy for job-seekers. Therefore, this study aims to provide basic data to address the psychological difficulties and stress problems of job-seekers by finding the effect of family health and psychological strength perceived by job-seekers on Job search efficacy. 


\subsection{Research Issue}

The purpose of this study is to analyze the relationship among job-seekers' perceived family health, psychological strength and Job search efficacy. The specific research questions are as follows.

First, What is the effect of job-seekers' perceived family health on Job search efficacy?

Second, What is the effect of job-seekers' psychological strength on Job search efficacy?

\section{Research method}

\subsection{Research Subjects}

The purpose of this study is to examine the effects of job seekers' perceived family health and psychological strength on job search efficacy. The study investigated 128 female job-seekers in their 40s to 50s those who are selected only answered sincerely out of 200 female job-seekers in Ulsan Metropolitan City from April 1, 2019 to May 30, 2019. The survey was conducted by self-registration formula after fully explaining the questionnaire's purpose to the subjects in advance. A total of 138 copies of the research data were collected, and 128 copies of the collected questionnaires, excluding those that were unfaithful or unsuitable for analysis, were collected and used for the analysis.

\subsection{Research Tool}

The tools used in this study consisted of three questions of demographic characteristics, 22 questions of perceived family health, 45 questions of psychological strength and 21 questions of Job search efficacy. The general characteristics were investigated by organizing gender, age, and monthly income levels. Measurement tools of 22 questions from Sung-hee Park(2017)[8], 45 questions from Kyung-ah Kim(2019)[11], and 21 questions from Hyun-chul Cho(2019)[12] were used in order to measure family health perceived by job seekers, psychological hardiness, job search efficacy, respectively. And each question was measured on a five-point of Likert scale. 


\subsection{Reliability}

[Table 1] Reliability of Major Variables

\begin{tabular}{ccc}
\hline division & Questions & Cronbach's $\alpha$ \\
\hline Perceived family health & 22 & .645 \\
Psychological strength & 45 & .741 \\
Job search efficacy & 21 & .626 \\
\hline
\end{tabular}

\subsection{Data Processing and Analysis Method}

The data collected in the study was verified at the significance level of 5\% using the SPSS 22.0 program, and the reliability calculation of each research tool was analyzed using a coefficient of Cronbach's a. A frequency analysis was used on the demographic characteristics of job-seekers, and correlation analyses were conducted on perceived family health, psychological strength, and Job search efficacy of job-seekers, and a regression analysis was performed to identify causality.

\section{Results}

\subsection{Demographic Characteristics}

Looking at the demographic characteristics of the subjects in this study, the gender of the job-seekers was found to have a higher percentage of women's responses, with 48 men (37.5\%) and 80 women $(62.5 \%)$. Those in their $40 \mathrm{~s}$ accounted for the largest share of 41 people (32.0 percent), followed by 32 people in their 50 s (25.0 percent), 25 people in their 20 s (19.5 percent), 16 people in their 30s (12.5 percent), and 14 people in their $60 \mathrm{~s}$ or older (10.9 percent). The monthly income level was the highest at 65 people (50.8 percent) with over 3 million won and under 3.99 million won, followed by 28 people (21.9 percent) with over 2 million won and under 2.99 million won, and 17 people (13.3 percent) with over 4 million won and under 4.99 million won.

[Table 2] Demographic Characteristics

\begin{tabular}{|c|c|c|c|}
\hline \multirow{2}{*}{\multicolumn{2}{|c|}{ Division }} & \multicolumn{2}{|c|}{ Overall(N=128) } \\
\hline & & \multirow{2}{*}{$\begin{array}{c}\text { frequency }(\mathrm{n}) \\
48\end{array}$} & \multirow{2}{*}{$\begin{array}{c}\text { ratio }(\%) \\
37.5\end{array}$} \\
\hline Sex & Male & & \\
\hline & Female & 80 & 62.5 \\
\hline
\end{tabular}




\begin{tabular}{c|c|c|c}
\hline \multirow{4}{*}{ Age } & $20 \mathrm{~s}$ & 25 & 19.5 \\
& $30 \mathrm{~s}$ & 16 & 12.5 \\
$40 \mathrm{~s}$ & 41 & 32.0 \\
$50 \mathrm{~s}$ & 32 & 25.0 \\
& $60 \mathrm{~s}$ or over & 14 & 10.9 \\
\hline \multirow{5}{*}{ Monthly income } & 1.67 million won or less & 1 & .8 \\
& 2.00 million won 2.99 milliion won & 2 & 1.6 \\
& 3.00 million won 3.99 milliion won & 65 & 21.9 \\
& 4.00 million won 4.99 milliion won & 17 & 50.8 \\
& 5.00 million won or over & 15 & 13.3 \\
\hline
\end{tabular}

\subsection{Technical Statistics on Major Variables}

\subsubsection{Technical Statistics on Perceived Family Health}

[Table 3] Technical Statistics on Perceived Family Health

\begin{tabular}{cccccc}
\hline Sortation & $\mathrm{N}$ & $\begin{array}{c}\text { Minimum } \\
\text { value }\end{array}$ & $\begin{array}{c}\text { Maximum } \\
\text { value }\end{array}$ & $\mathrm{M}$ & $\mathrm{SD}$ \\
\hline Family elasticity & 128 & 1.43 & 4.29 & 3.12 & .51 \\
Mutual respect and acceptance & 128 & 2.20 & 5.00 & 3.71 & .63 \\
Qualitative bonding & 128 & 2.00 & 5.00 & 3.41 & .59 \\
Economic stability and cooperation & 128 & 2.00 & 5.00 & 3.41 & .54 \\
Family culture and social participation & 128 & 1.67 & 5.00 & 3.30 & .68 \\
Perceived family health(Full) & 128 & 1.93 & 4.86 & 3.39 & .48 \\
\hline
\end{tabular}

\subsubsection{Technical Statistics on Psychological Strength}

[Table 4] Technical Statistics on Psychological Strength

\begin{tabular}{cccccc}
\hline Sortation & $\mathrm{N}$ & $\begin{array}{c}\text { Minimum } \\
\text { value }\end{array}$ & $\begin{array}{c}\text { Maximum } \\
\text { value }\end{array}$ & $\mathrm{M}$ & $\mathrm{SD}$ \\
\hline Involvement & 128 & 2.47 & 4.13 & 3.43 & .38 \\
Control & 128 & 2.60 & 4.33 & 3.51 & .36 \\
Challenge & 128 & 2.33 & 3.53 & 2.87 & .24 \\
Psychological strenth (Full) & 128 & 2.60 & 3.87 & 3.27 & .26 \\
\hline
\end{tabular}




\subsubsection{Technical Statistics on Job Search Efficacy}

The measurement variables for job-seekers' effectiveness were measured on a 5-point scale. Looking at the Job search efficacy factors, we can see that the minimum value was 2.67 and the maximum value was 4.33 , and that the overall Job search efficacy $(M=3.45)$ factor was higher than the average score. The results of the technical statistics on the effectiveness of job-seekers are shown in Table 5.

[Table 5] Technical Statistics on Job Search Efficacy

\begin{tabular}{cccccc}
\hline Sortation & $\mathrm{N}$ & $\begin{array}{c}\text { Minimum } \\
\text { value }\end{array}$ & $\begin{array}{c}\text { Maximum } \\
\text { value }\end{array}$ & $\mathrm{M}$ & $\mathrm{SD}$ \\
\hline Job search efficacy & 128 & 2.67 & 4.33 & 3.45 & .42 \\
\hline
\end{tabular}

\subsection{Correlation between Variables}

[Table 6] Correlation between Major Variables

\begin{tabular}{cccc}
\hline Sortation & Perceived family health & Psychological strength & Job search efficacy \\
\hline Perceived family health & 1 & & \\
Psychological strengthl & $.543^{* *}$ & 1 & 1 \\
Job search efficacy & $.594^{* *}$ & $.532^{* *}$ & \\
\hline${ }^{*}<<.05,{ }^{* *} \mathrm{p}<.01$ & & &
\end{tabular}

\subsection{Effects of Perceived Family Health and Psychological Strength of Job Seekers on Job Search Efficacy}

\subsubsection{Effects of Perceived Family Health of Job Seekers on Job Search Efficacy}

Multiple regression analyses were conducted to find out the effects of perceived family health of job-seekers on their Job search efficacy. According to the analysis, the R2 value, which refers to the ability to explain the perceived family health of job seekers, is .545 and indicates a regression model with $54.5 \%$ of the total variability. In addition, the D-W (Durbin Watson) value is 1.454 and is not close to zero or four, so there is no auto-correlation, the tolerance 
limit was 0.1 or higher, and the VIF value was less than or equal to 10 . The regression model estimated as a result of the ANOVA on the model $(\mathrm{F}=29.211, \mathrm{p}<.000)$ was shown to be statistically significant. The influence of each sub-factor of perceived family health is as follows. The three factors, mutual respect and acceptance $(\beta=.409, \mathrm{p}<.01)$, economic stability and cooperation $(\beta=.192, p<.05)$, family culture and social participation $(\beta=.265, p<.01)$, were found to have a positive $(+)$ effect on job search efficacy on statistical significance level. On the other hand, family elasticity $(\beta=.121, \mathrm{p}>.05)$ and qualitative bonding $(\beta=-.351, \mathrm{p}>.05)$ factors are shown to have no significant impact on Job search efficacy. This means that the higher the factors of mutual respect and acceptance, economic stability and cooperation, and family culture and social participation, which are the sub-factors of the perceived family health of the job-seekers are, the higher the self-effectiveness is.

\subsubsection{Effects of Psychological Strength of Job-seekers on Job Search Efficacy}

Multiple regression analyses were conducted to find out the effects of psychological strength of the job-seekers on their Job search efficacy. According to the analysis, the R2 value, which refers to the psychological strength of self-effectiveness, is .495 and describes the regression model as $49.5 \%$ of the total variability. In addition, the D-W (Durbin Watson) value is 2.044, so there is no auto-correlation, the tolerance limit was 0.1 or higher, and the VIF value is 10 or less than 10. The regression model estimated as a result of the ANOVA on the model $(\mathrm{F}=40.454, \mathrm{p}<.000)$ was shown to be statistically significant. To look at the influence of each sub-factor of psychological strength, control $(\beta=.597, \mathrm{p}<.001)$ factor has been shown to have a static $(+)$ effect on self-effectiveness at a statistical significance level. On the other hand, involvement $(\beta=-.110, p>.05)$, Challenge $(\beta=-.212, p>.05)$ factors are shown to have no significant effect on self-effectiveness. This means that the higher the control factor, which is the sub-factor of the psychological strength of the job-seeker is, the higher Job search efficacy is.

\section{Conclusion and Suggestion}

In this study, the effects of perceived family health, psychological strength, and Job search efficacy of job-seekers were analyzed. Based on the analysis results, the detailed discussion is as follows.

First, an analysis of the influence of the job-seekers' perceived family health and Job search efficacy showed that the factors of mutual respect and acceptance, economic stability and 
cooperation, family culture and social participation, which are sub-factories of perceived family health, had a positive and significant effect on self-effectiveness. On the other hand, family elasticity and qualitative bonding factors have been found to have no significant impact on Job search efficacy. This means that the higher the factors of mutual respect and acceptance, economic stability and cooperation, and family culture and social participation, which are the sub-factors of the perceived family health of the job-seekers, are, the more the Job search efficacy is. These results mean that the higher the factors of mutual respect and acceptance, economic stability and cooperation, and family culture and social participation, which are sub-factors of perceived family health for job-seekers, are, the higher the Job search efficacy is. On the other hand, family elasticity and qualitative bonding factors have been found to have no significant impact on Job search efficacy.

Second, an analysis of the influence of the work-seekers' psychological strength and Job search efficacy shows that the control factor among the sub-factors of psychological strength has a positive and significant effect on self-effectiveness. On the other hand, factors of involvement and challenge have shown no significant impact on Job search efficacy. This means that the higher the control factor, which is the sub-factor of the psychological strength for the job-seekers, is, the higher Job search efficacy is. On the other hand, the factors of involvement and challenge have shown no significant impact on Job search efficacy.

As discussed above, it is important to develop and research programs that can solve various problems as well as improve job seekers' efficacy, not only in terms of social welfare services o $\mathrm{f}$ job seekers. Based on these research results, systematic content development and in-depth rese arch are required for job seekers.

\section{References}

[1] Han-joon Kim, The Influence of the Fourth Industrial Revolution on the Job World, Announcement of the Korea Agricultural and Educational Association's Conference, (2017), June 22, Seoul, Korea.

[2] Hye-jung Gwak, The Influence of Job Information Recognition Level on Job Behavior by the Unemployed: Focused on the Mediation Effect of Job Effectiveness, Daegu University, Master's Thesis, (2011)

[3] Jung-hyun Cho, Jong-woon Park, Hyo-heon Won, The Effect of Self-efficacy and Social support on Job-seeking efficacy of Job Seekers, Journal of Fisheries and Marine Sciences Education, (2018), Vol.30, No.3, pp.796-806.

[4] Kang-hee Goo, Effects of career-determined self-efficacy and social support on career-dissipating women's job-seeking behavior, Kookmin University, Master's Thesis, (2018) 
[5] Hana Bum, The Effect of Job Support Program on the Self-Effectiveness of Women's University, Job Efficiency, and Job Preparation Behavior of Women's University: Focused on Job Education Program, Ewha Womans University, Master's Thesis,, (2018)

[6] Pil-ju Ham, Ki-jung Kang, The Influence of Self-esteem, Family Support and Employment Preparation on Job-seeking Efficacy of Married Female Immigrants, Korean Journal of Family Welfare, (2015), Vol.20, No.3, pp.525-541.

[7] Hyun-mi Lee, The effect of social support of re-employment workers on career maturity and the mediating effect of job efficacy, Chung-Ang University, Master's Thesis, (2014)

[8] Sung-hee Park, The Impact of Peer Counseling Program on Adolescents' Development in Empathic Ability, Peer Support, and School Violence Attitude,, Korean Journal of Youth Studies, (2017), Vol.24, No.9, pp.1-30.

[9] Ji-yeon Kim, Gi-hak Lee, The Influence of Ego-Resilience and Career Decision Self-Efficacy on Career Preparation Behavior: Testing the Moderated Mediating Effect of Achievement Motivation, The Journal of Career Education Research, (2014), Vol.27, No.3, pp.1-25.

[10] Shin-young Park, An Analysis of a Mediation Effect that Social Support has on Relationship between Positive Psychology Capital and Career Preparation Behavior perceived by Students in College of Education, The Journal of Learner-Centered Curriculum and Instruction, (2017), Vol.17, pp.169-193.

[11] Kyung-ah Kim, Effect of daily Stress on Mental Health Problems and Mental Well-being: Focused on the Moderating Effect of Hardiness, Seoul Graduate School of Counseling Psychology, Doctoral Dissertation, (2019)

[12] Hyun-Chul Jo, The Influence of Client Violence on Psychological Stability of Social Workers - Focusing on the Moderating Effects of Self-Efficacy and Resilience, Daejeon University, Doctoral Dissertation, (2019) 